\title{
Editorial
}

\section{Is Depression the Wrong Treatment Target for Improving Outcome in Coronary Artery Disease?}

\author{
Chiara Rafanellia, b Laura Sirria, ${ }^{a}$ Silvana Grandia, ${ }^{a} \quad$ Giovanni A. Fava ${ }^{a-c}$ \\ a Department of Psychology and ${ }^{b}$ Laboratory of Psychosomatics and Clinimetrics, University of Bologna, \\ Bologna, Italy; ${ }^{C}$ Department of Psychiatry, State University of New York at Buffalo, Buffalo, N.Y., USA
}

A significant relationship between depression and cardiac morbidity has been documented [1]. The identification of depression as an unfavorable marker of the clinical course in coronary artery disease (CAD) in the 1990s [24] generated the hope of improving the prognosis of cardiovascular disease with treatment of depression. This hope, however, has not survived the test of time. In a Cochrane review on randomized controlled clinical trials (RCTs) of any length of treatment and any length of follow-up [5], psychological and pharmacological interventions have shown a small yet clinically meaningful effect on depression outcomes in CAD patients. However, no beneficial effects on the reduction of mortality rates and cardiac events have been found. Indeed, in some cases, treatment of depression was found to entail negative physical consequences. There are several potential explanations, involving drugs and psychotherapy, which account for this phenomenon.

\section{The Failure of Antidepressant Drugs}

The evidence that is available in psychiatric settings suggests that the positive effects of antidepressant drugs are related to symptom severity [6]. Indeed, the Sertraline Antidepressant Heart Attack Randomized Trial (SAD-
HART) [7], on depressed patients after CAD, found that the effect of sertraline was greater in patients with severe and recurrent depression. It is also true that, in cardiac settings, mild depressive symptoms are sufficient to enhance cardiovascular risk even in the absence of major depressive disorder [8-11]. Antidepressant treatment could thus be successful in terms of cardiac prognosis only in the subgroup of cardiac patients with more severe depression, but not in those with milder depression at equally elevated cardiac risk.

It has been suggested that selective serotonin reuptake inhibitors (SSRIs) might ameliorate the adverse effect of depression on cardiovascular disease through the inhibition of platelet aggregation, even independently of changes in depression [12]. This potential benefit, however, is counteracted by recognized adverse cardiovascular side effects [13-15]. In particular, the use of SSRIs such as citalopram and escitalopram is associated with cases of arrhythmias and prolonged QTc interval on electrocardiogram in patients lacking cardiovascular disorders [16]. Licht et al. [17] found that all antidepressants, including SSRIs, have a lowering effect on cardiac vagal control that has been found to be associated with increased blood pressure and other metabolic abnormalities, such as unfavorable lipid profiles and high glucose levels [18].

\section{KARGER}

E-Mail karger@karger.com

www.karger.com/pps
(C) 2013 S. Karger AG, Basel

0033-3190/13/0825-0285\$38.00/0
Chiara Rafanelli, $\mathrm{MD}, \mathrm{PhD}$

Department of Psychology, University of Bologna Viale Berti Pichat 5

IT-40127 Bologna (Italy)

E-Mail chiara.rafanelli@unibo.it 
It is also well recognized that the potential for drugdrug interactions increases with the number of medication used [19] and this is a common problem for cardiac patients. Labos et al. [20] found that the use of an SSRI combined with dual antiplatelet therapy (including clopidogrel and ASA) was associated with an increased risk of gastrointestinal bleeding, hemorrhagic stroke or other bleeding that either necessitated admission to hospital or occurred in hospital during follow-up, compared with ASA use alone. Again, such drug-drug interactions may counteract the potential benefits of SSRIs on platelet aggregation.

The modest effects of antidepressant drugs in improving depression and the lack of effects on cardiovascular prognosis may also depend on the loss of clinical effects refractory to dosage increase, with enhanced susceptibility to subsequent episodes of depression, observed after long-term use of antidepressant drugs [21]. In patients with bipolar illness, these phenomena may involve switching into mania/hypomania and/or episode acceleration [21] and account for the failure of antidepressant drugs to improve long-term cardiovascular outcome.

\section{The Failure of Psychotherapy Trials}

On the whole, standardized approaches for the treatment of depression by psychotherapy have also failed to provide benefit to cardiac patients in clinical trials. The ENRICHD study [22] found significant improvements in patients' levels of depression and social support 6 months after initiation of cognitive-behavior therapy (CBT) compared with care as usual, even though differences between the arms diminished over time and were no longer present at 30 months. It is likely that the approach failed to affect cardiac prognosis due to the short-term nature of the effects.

In the same vein, the CREATE study [23] found no advantage in reducing depression with a dozen 50-min sessions of interpersonal psychotherapy (IPT) compared with weekly 20 -min clinical management sessions with clinicians who encouraged adherence and gave information about depression, discussed medication use and provided reassurance [24]. The results of this trial suggested the possibility of the unfavorable effects of psychological treatment on both depression and the cardiocirculatory system. In fact, patients randomized to IPT reported fatigue more frequently than those assigned to clinical management. They also experienced a slight increase in systolic blood pressure at 12 weeks in comparison to a slight decrease among patients receiving clinical management alone [23]. These negative effects could be partially explained by the reported paradoxically higher level of initial social adjustment as a predictor of a good response to IPT [25], even though the theoretical basis of IPT would suggest greater effectiveness in patients with lower levels of social functioning [26]. This critical issue should thus be examined in future research on the evaluation of the efficacy of IPT on both depression and survival in cardiac patients. Another important aspect to be considered in the light of the negative results of treatments for depression, such as IPT, is that cardiac depressed patients in $14 \%$ of cases do not adhere to their prescribed medication regimen [27]. This could explain the positive effects of sessions of clinical management based on encouraging adherence compared to IPT in the CREATE trial.

There is also the need to consider that certain treatments could be unsuitable for CAD patients. In fact, most of the depression interventions, used in the cited trials involving patients with $\mathrm{CAD}$, were originally validated with outpatients with psychiatric problems seeking treatment. Therefore, acceptance by the broader population of patients with CAD cannot be assumed [22], as cardiac patients often do not agree with a diagnosis of depression nor do they seek treatment for depression [28]. The issue of satisfaction with treatment has been the focus of the Coronary Psychosocial Evaluation Studies (COPES) RCT [28]. An enhanced care intervention based on both the preference of the patients and the severity of depression was more accepted by CAD depressed subjects in comparison with usual care and significantly reduced depressive symptoms and major adverse cardiac events. Moreover, the authors of the cited study chose to include a 3 -month observation period to identify patients with persistent depressive symptoms and thereby decreased the likelihood of a large reduction in depressive symptoms in the control group [28].

\section{Is Depression the Right Target?}

Another potential explanation for the failure of the treatment of depression to improve outcome in CAD is the fact that only some depressed cardiac patients may be at a high risk of morbidity and mortality. If there is a highrisk subtype of depression, it could be underrepresented in some studies and overrepresented in others [29], giving different results in RCTs. Certain clusters of symptoms could be more relevant for cardiac prognosis than others. For example, anhedonia and somatic symptoms, such as 
sleeping difficulties and fatigue, were found to be more 'cardiotoxic' than cognitive symptoms [30-34]. Thus, the treatment of depression is unlikely to ameliorate cardiac prognosis without a significant reduction of such symptoms. These harmful symptoms could represent specific targets for interventions that may be different from interventions derived from general psychiatry [32]. On the other hand, cardiovascular risk could be the result of an association between typical symptoms of depression and other conditions, that were not considered so far as targets of treatment, such as vital exhaustion $[35,36]$, hopelessness [37-39], demoralization [40,41], pessimism [42, 43] and rumination [44].

In the same vein, it is likely that psychotherapy protocols focusing on depressive symptoms in cardiac settings may overlook other important negative affective components associated with depression, such as anxiety, anger, hostility, distress or a general disposition toward negative affectivity and personality traits [43, 45-52]. These components that are associated with depression, if untreated, could interfere with medical outcomes due to a combination of the effects on inflammation, catecholamines, heart-rate variability and endothelial function, along with effects on health-promoting behaviors [53].

The most substantial benefits in relapse prevention of depression have been obtained with a sequential combination of treatment strategies encompassing a broad spectrum of therapeutic targets $[54,55]$. CBT applied to patients who had remitted upon pharmacotherapy yielded significant advantages in the sequential approach, both in terms of relapse rate and/or residual symptomatology, compared with clinical management or treatment as usual. The focus of CBT should be both on deficits and enhancing strengths and potentialities, as evidence exists that certain dimensions of psychological well-being, such as a purpose in life, may play an important role in protecting against myocardial infarction [56]. Treatments specifically addressing the enhancement of positive functioning could give better results in terms of cardiac prognosis, even though this is yet to be tested.

\section{Type A Behavior: A Reassessment Is Overdue}

Ormel and de Jonge [57] suggested that the most plausible pathways mediating the effects of persistent/recurrent depression (apart from the type) on cardiac prognosis are behavioral, and act by making depressed CAD patients more susceptible to other CAD risk factors. It is thus not surprising that psychotherapeutic treatments specifically geared to lifestyle modification have achieved impressive results in CAD [58-60]. A low-fat vegetarian diet, smoking cessation, stress management training and moderate exercise turned out to be effective secondary prevention strategies of CAD in several clinical trials [58, 61-67], leading to a significant decrease in coronary atherosclerosis, rehospitalizations and cardiovascular events.

One of the components addressed in some of the studies is type A behavior [68] - a set of psychological features such as free-floating hostility, time urgency and competitiveness - that was found to be significantly associated with an increased risk of cardiovascular disease [69]. Since the 1980s, hostility has emerged as the most important feature [70]. However, interpretation of many studies has been complicated by the use of self-rating instruments, which neither capture the motor-expressive features of type A behavior nor determine its prevalence. This psychological construct is thus often discarded as an obsolete formulation. There is evidence, however, for calling such views into question. On the basis of original descriptions and the most relevant studies on type $\mathrm{A}$, in the Diagnostic Criteria for Psychosomatic Research (DCPR) [71-73] nine items were identified to diagnose type A behavior. According to the DCPR, patients with cardiac conditions who presented type A (up to one third of the population) tended to display minimization of psychological impact and possible life-threatening consequences of cardiac disease [74]. This finding is in line with previous studies documenting an overlap between type A behavior and both hypomania and hyperthymic temperament, which are subclinical manifestations of the bipolar spectrum [75-77]. Such association could explain both an increased cardiac risk in patients with bipolar disorders [78, 79] and a lack of improvement in cardiac prognosis after the treatment of depression. In CAD patients with type A behavior, depressive symptoms following a cardiovascular event may thus be part of a subsyndromal bipolar disorder.

More literature is appearing on the detrimental effects of the pharmacological treatment of depression in the course of bipolar disorder [21, 80]. When patients with type A behavior become depressed, improvement of mood may bring the patient back to the hypomanic condition. Thus, moving from physical inactivity to exhausting exercise or from anhedonia to excessive work involvement may have a detrimental effect on cardiac prognosis. The lack of benefits evident in heterogeneous samples may result from a balance between beneficial and harmful effects in different subgroups [81]. In depressed patients with a history of type A behavior, use of mood-elevating 
strategies may be contraindicated. Psychotherapeutic strategies aimed at preventing reassumption of hypomanic features, particularly if they are concerned with illness behavior including underestimation of vulnerability to unhealthy habits and illness progression [82], may be more suitable. These patients should not be encouraged to return to their premorbid functioning, but rather to adopt a more adaptive lifestyle [83], e.g. developing the ability to recognize tiredness and take a rest. A Cochrane review by Whalley et al. [84] underlines that psychological treatments in cardiac patients are more effective in lowering depression if they include type A behavior among their therapeutic targets. Thus, the treatment of depression without addressing an inappropriate premorbid lifestyle may actually worsen the course of CAD in the subgroup of patients who display type A behavior.

Even though in the last decades type A behavior has attracted limited research interest, there is evidence suggesting that its modification through cognitive-behavioral strategies may lead to a significantly lower risk of cardiac recurrences $[68,85,86]$.

It should be noted that many of the controversial results of research on type A behavior in cardiovascular disease may be due to an excessive reliance on questionnaires that miss the clinical and observational features which formed the basis of original observations [87]. The DCPR criteria for type A behavior incorporate such clinical information [71].

\section{Future Prospects}

Depression has attracted a considerable amount of research and funding in CAD. However, RCTs have failed to document a significant effect of its treatment on sub- sequent prognosis of $\mathrm{CAD}$, and the clinical implications of massive research are at present negligible. The role of depression and the use of antidepressant drugs have been supported by extensive pharmaceutical propaganda [88] Indeed, the use of antidepressants in cardiology settings has risen dramatically since the early 1990s [89]. The basic message sold to the physicians was that a better cardiovascular outcome could be obtained by treating depression even in its milder forms with readily available medications. Depression was assimilated to 'bad cholesterol' and antidepressant drugs to statins, which noone should be refused (well beyond the original indications). Type A behavior did not fit with this promotional picture and was thus censored by the special-interest groups that control medical information [88].

The time has come, however, to question the massive use of antidepressant drugs in cardiology settings and the current research priorities that do not acknowledge type A behavior, lifestyle and the longitudinal course of mood disorders [90]. Depression in CAD may simply be the final common pathway of a number of psychosomatic developments and may be a partial and misleading target for treatment. Both psychosocial assessment and intervention in cardiac patients should incorporate a wider range of clinical phenomena which may interact with depressive symptomatology and its treatment. Such phenomena include type A behavior, lifestyle, illness behavior and psychological well-being $[90,91]$.

\section{Acknowledgments}

This study was supported in part by a grant to C.R. from the Compagnia di San Paolo, Torino, Italy, who also supported the fellowship of L.S.

\section{References}

1 Baune BT, Stuart M, Gilmour A, Wersching $\mathrm{H}$, Arolt V, Berger K: Moderators of the relationship between depression and cardiovascular disorders: a systematic review. Gen Hosp Psychiatry 2012;34:478-492.

-2 Ladwig KH, Kieser M, König J, Breithardt G, Borggrefe M: Affective disorders and survival after acute myocardial infarction. Results from the post-infarction late potential study. Eur Heart J 1991;12:959-964.

3 Frasure-Smith N, Lespérance F, Talajic M: Depression following myocardial infarction. Impact on 6-month survival. JAMA 1993;270: 1819-1825.
4 Frasure-Smith N, Lespérance F, Talajic M: Depression and 18-month prognosis after myocardial infarction. Circulation 1995;91: 999-1005.

5 Baumeister H, Hutter N, Bengel J: Psychological and pharmacological interventions for depression in patients with coronary artery disease. Cochrane Database Syst Rev 2011; 9:CD008012

-6 Fournier JC, DeRubeis RJ, Hollon SD, Dimidjian S, Amsterdam JD, Shelton RC, Fawcett J: Antidepressant drug effects and depression severity: a patient-level meta-analysis. JAMA 2010;303:47-53.
7 Glassman AH, O'Connor CM, Califf RM, Swedberg K, Schwartz P, Bigger JT Jr, Krishnan KR, van Zyl LT, Swenson JR, Finkel MS, Landau C, Shapiro PA, Pepine CJ, Mardekian J, Harrison WM, Barton D, Mclvor M: Sertraline treatment of major depression in patients with acute MI or unstable angina. JAMA 2002;288:701-709.

-8 Bush DE, Ziegelstein RC, Tayback M, Richter D, Stevens S, Zahalsky H, Fauerbach JA: Even minimal symptoms of depression increase mortality risk after acute myocardial infarction. Am J Cardiol 2001;88:337-341. 
$\checkmark 9$ Lespérance F, Frasure-Smith N, Talajic M, Bourassa MG: Five-year risk of cardiac mortality in relation to initial severity and oneyear changes in depression symptoms after myocardial infarction. Circulation 2002;105: 1049-1053.

10 Rafanelli C, Roncuzzi R, Milaneschi Y: Minor depression as a cardiac risk factor after coronary artery bypass surgery. Psychosomatics 2006;47:289-295.

11 Rafanelli C, Milaneschi Y, Roncuzzi R, Pancaldi LG: Dysthymia before myocardial infarction as a cardiac risk factor at 2.5-year follow-up. Psychosomatics 2010;51:8-13.

-12 Serebruany VL, Glassman AH, Malinin AI, Nemeroff CB, Musselman DL, van Zyl LT, Finkel MS, Krishnan KR, Gaffney M, Harrison W, Califf RM, O'Connor CM: Platelet/ endothelial biomarkers in depressed patients treated with the selective serotonin reuptake inhibitor sertraline after acute coronary events: the Sertraline AntiDepressant Heart Attack Randomized Trial (SADHART) Platelet Substudy. Circulation 2003;108:939-944.

-13 Pacher P, Kecskemeti V: Cardiovascular side effects of new antidepressants and antipsychotics: new drugs, old concerns? Curr Pharm Des 2004;10:2463-2475.

-14 Kanjanauthai S, Kanluen T, Chareonthaitawee P: Citalopram-induced torsade de pointes, a rare life-threatening side effect. Int J Cardiol 2008;131:e33-e34.

15 Weeke P, Jensen A, Folke F, Gislason GH, Olesen JB, Andersson C, Fosbøl EL, Larsen JK, Lippert FK, Nielsen SL, Gerds T, Andersen PK, Kanters JK, Poulsen HE, Pehrson S, Køber L, Torp-Pedersen C: Antidepressant use and risk of out-of-hospital cardiac arrest: a nationwide case-time-control study. Clin Pharmacol Ther 2012;92:72-79.

16 Castro VM, Clements CC, Murphy SN, Gainer VS, Fava M, Weilburg JB, Erb JL, Churchill SE, Kohane IS, Iosifescu DV, Smoller JW, Perlis RH: QT interval and antidepressant use: a cross-sectional study of electronic health records. BMJ 2013;346:f288.

17 Licht CM, de Geus EJ, van Dyck R, Penninx BW: Longitudinal evidence for unfavorable effects of antidepressants on heart rate variability. Biol Psychiatry 2010;68:861-868.

- 18 Licht CM, Vreeburg SA, van Reedt Dortland AK, Giltay EJ, Hoogendijk WJ, DeRijk RH, Vogelzangs N, Zitman FG, de Geus EJ, Penninx BW: Increased sympathetic and decreased parasympathetic activity rather than changes in hypothalamic-pituitary-adrenal axis activity is associated with metabolic abnormalities. J Clin Endocrinol Metab 2010;95:2458-2466.

19 Dhabali AA, Awang R, Zyoud SH: Clinically important drug-drug interactions in primary care. J Clin Pharm Ther 2012;37:426-430.

20 Labos C, Dasgupta K, Nedjar H, Turecki G, Rahme E: Risk of bleeding associated with combined use of selective serotonin reuptake inhibitors and antiplatelet therapy following acute myocardial infarction. CMAJ 2011;183: 1835-1843.
21 Fava GA, Offidani E: The mechanisms of tolerance in antidepressant action. Prog Neuropsychopharmacol Biol Psychiatry 2011;35: 1593-1602.

22 Berkman LF, Blumenthal J, Burg M, Carney RM, Catellier D, Cowan MJ, Czajkowski SM, DeBusk R, Hosking J, Jaffe A, Kaufmann PG, Mitchell P, Norman J, Powell LH, Raczynski JM, Schneiderman N: Effects of treating depression and low perceived social support on clinical events after myocardial infarction: the Enhancing Recovery in Coronary Heart Disease Patients (ENRICHD) Randomized Trial. JAMA 2003;289:3106-3116.

23 Lespérance F, Frasure-Smith N, Koszycki D, Laliberté MA, van Zyl LT, Baker B, Swenson JR, Ghatavi K, Abramson BL, Dorian P, Guertin MC: Effects of citalopram and interpersonal psychotherapy on depression in patients with coronary artery disease: the Canadian Cardiac Randomized Evaluation of Antidepressant and Psychotherapy Efficacy (CREATE) trial. JAMA 2007;297:367-379.

24 Glassman AH, Bigger JT Jr: Antidepressants in coronary heart disease: SSRIs reduce depression, but do they save lives? JAMA 2007; 297:411-412.

25 Sotsky SM, Glass DR, Shea MT, Pilkonis PA, Collins JF, Elkin I, Watkins JT, Imber SD, Leber WR, Moyer J, Oliveri ME: Patient predictors of response to psychotherapy and pharmacotherapy: findings in the NIMH Treatment of Depression Collaborative Research Program. Am J Psychiatry 1991;148: 997-1008.

26 Parker G, Parker I, Brotchie H, Stuart S: Interpersonal psychotherapy for depression? The need to define its ecological niche. J Affect Disord 2006;95:1-11.

27 Gehi A, Haas D, Pipkin S, Whooley MA: Depression and medication adherence in outpatients with coronary heart disease: findings from the Heart and Soul Study. Arch Intern Med 2005;165:2508-2513.

28 Davidson KW, Rieckmann N, Clemow L, Schwartz JE, Shimbo D, Medina V, Albanese G, Kronish I, Hegel M, Burg MM: Enhanced depression care for patients with acute coronary syndrome and persistent depressive symptoms: coronary psychosocial evaluation studies randomized controlled trial. Arch Intern Med 2010;170:600-608.

29 Carney RM, Freedland KE: Is there a highrisk subtype of depression in patients with coronary heart disease? Curr Psychiatry Rep 2012;14:1-7.

30 Doyle F, Conroy R, McGee H, Delaney M: Depressive symptoms in persons with acute coronary syndrome: specific symptom scales and prognosis. J Psychosom Res 2010;68:121130. de Jonge P, Ormel J, van den Brink RH, van Melle JP, Spijkerman TA, Kuijper A, van Veldhuisen DJ, van den Berg MP, Honig A, Crijns HJ, Schene AH: Symptom dimensions of depression following myocardial infarction and their relationship with somatic health status and cardiovascular prognosis. Am J Psychiatry 2006;163:138-144.

32 Martens EJ, Hoen PW, Mittelhaeuser M, de Jonge P, Denollet J: Symptom dimensions of post-myocardial infarction depression, disease severity and cardiac prognosis. Psychol Med 2010;40:807-814.

33 Roest AM, Thombs BD, Grace SL, Stewart DE, Abbey SE, de Jonge P: Somatic/affective symptoms, but not cognitive/affective symptoms, of depression after acute coronary syndrome are associated with 12-month allcause mortality. J Affect Disord 2011;131: 158-163.

34 Bekke-Hansen S, Trockel M, Burg MM, Taylor CB: Depressive symptom dimensions and cardiac prognosis following myocardial infarction: results from the ENRICHD clinical trial. Psychol Med 2012;42:51-60.

35 Appels A, Mulder P: Excess fatigue as a precursor of myocardial infarction. Eur Heart J 1988;9:758-764.

36 Kop WJ, Appels AP, Mendes de Leon CF, de Swart HB, Bär FW: Vital exhaustion predicts new cardiac events after successful coronary angioplasty. Psychosom Med 1994;56:281287.

37 Anda R, Williamson D, Jones D, Macera C, Eaker E, Glassman A, Marks J: Depressed affect, hopelessness, and the risk of ischemic heart disease in a cohort of U.S. adults. Epidemiology 1993;4:285-294.

38 Everson SA, Goldberg DE, Kaplan GA, Cohen RD, Pukkala E, Tuomilehto J, Salonen JT: Hopelessness and risk of mortality and incidence of myocardial infarction and cancer. Psychosom Med 1996;58:113-121.

39 Pedersen SS, Denollet J, Daemen J, van de Sande M, de Jaegere PT, Serruys PW, Erdman RA, van Domburg RT: Fatigue, depressive symptoms, and hopelessness as predictors of adverse clinical events following percutaneous coronary intervention with paclitaxeleluting stents. J Psychosom Res 2007;62:455461.

-40 Rafanelli C, Roncuzzi R, Milaneschi Y, Tomba E, Colistro MC, Pancaldi LG, Di Pasquale G: Stressful life events, depression and demoralization as risk factors for acute coronary heart disease. Psychother Psychosom 2005; 74:179-184.

41 Grandi S, Sirri L, Tossani E, Fava GA: Psychological characterization of demoralization in the setting of heart transplantation. J Clin Psychiatry 2011;72:648-654

42 Kubzansky LD, Sparrow D, Vokonas P, Kawachi I: Is the glass half empty or half full? A prospective study of optimism and coronary heart disease in the normative aging study. Psychosom Med 2001;63:910-916. 
43 Shen BJ, McCreary CP, Myers HF: Independent and mediated contributions of personality, coping, social support, and depressive symptoms to physical functioning outcome among patients in cardiac rehabilitation. J Behav Med 2004;27:39-62.

44 Larsen BA, Christenfeld NJ: Cardiovascular disease and psychiatric comorbidity: the potential role of perseverative cognition. Cardiovasc Psychiatry Neurol DOI: 10.1155/ 2009/791017.

$\checkmark 45$ Strik JJ, Denollet J, Lousberg R, Honig A: Comparing symptoms of depression and anxiety as predictors of cardiac events and increased health care consumption after myocardial infarction. J Am Coll Cardiol 2003;42: 1801-1807.

46 Suls J, Bunde J: Anger, anxiety, and depression as risk factors for cardiovascular disease: the problems and implications of overlapping affective dispositions. Psychol Bull 2005;131: 260-300.

-47 Chida Y, Steptoe A: The association of anger and hostility with future coronary heart disease: a meta-analytic review of prospective evidence. J Am Coll Cardiol 2009;53:936-946.

48 Janszky I, Ahnve S, Lundberg I, Hemmingsson T: Early-onset depression, anxiety, and risk of subsequent coronary heart disease: 37 year follow-up of 49,321 young Swedish men. J Am Coll Cardiol 2010;56:31-37.

-49 Kronish IM, Chaplin WF, Rieckmann N, Burg MM, Davidson KW: The effect of enhanced depression care on anxiety symptoms in acute coronary syndrome patients: findings from the COPES trial. Psychother Psychosom 2012;81:245-247.

50 Denollet J, Sys SU, Brutsaert DL: Personality and mortality after myocardial infarction. Psychosom Med 1995;57:582-591.

- 51 Beutel ME, Wiltink J, Till Y, Wild PS, Münzel T, Ojeda FM, Zeller T, Schnabel RB, Lackner K, Blettner M, Zwiener I, Michal M: Type D personality as a cardiovascular risk marker in the general population: results from the Gutenberg health study. Psychother Psychosom 2012;81:108-117.

52 Lee HB, Bienvenu OJ, Cho SJ, Ramsey CM, Bandeen-Roche K, Eaton WW, Nestadt G: Personality disorders and traits as predictors of incident cardiovascular disease: findings from the 23-year follow-up of the Baltimore ECA study. Psychosomatics 2010;51:289296.

53 Huffman JC, Celano CM, Januzzi JL: The relationship between depression, anxiety, and cardiovascular outcomes in patients with acute coronary syndromes. Neuropsychiatr Dis Treat 2010;6:123-136.

54 Rafanelli C, Fava GA, Sonino N: Sequential treatment of depression in primary care. Int $\mathrm{J}$ Clin Pract 2007;61:1719-1729.

55 Fava GA, Tomba E: New modalities of assessment and treatment planning in depression: the sequential approach. CNS Drugs 2010;24: 453-465.
56 Kim ES, Sun JK, Park N, Kubzansky LD, Peterson C: Purpose in life and reduced risk of myocardial infarction among older U.S. adults with coronary heart disease: a two-year follow-up. J Behav Med 2013;36:124-133.

57 Ormel J, de Jonge P: Unipolar depression and the progression of coronary artery disease: toward an integrative model. Psychother Psychosom 2011;80:264-274.

58 Ornish D, Scherwitz LW, Billings JH, Brown SE, Gould KL, Merritt TA, Sparler S, Armstrong WT, Ports TA, Kirkeeide RL, Hogeboom C, Brand RJ: Intensive lifestyle changes for reversal of coronary heart disease. JAMA 1998;280:2001-2007.

59 Cole JA, Smith SM, Hart N, Cupples ME: Systematic review of the effect of diet and exercise lifestyle interventions in the secondary prevention of coronary heart disease. Cardiol Res Pract 2010;2011:232351.

60 Janssen V, Gucht VD, Dusseldorp E, Maes S: Lifestyle modification programmes for patients with coronary heart disease: a systematic review and meta-analysis of randomized controlled trials. Eur J Prev Cardiol 2012, Epub ahead of print.

61 Ornish D, Brown SE, Scherwitz LW, Billings JH, Armstrong WT, Ports TA, McLanahan SM, Kirkeeide RL, Brand RJ, Gould KL: Can lifestyle changes reverse coronary heart disease? The Lifestyle Heart Trial. Lancet 1990;336:129-133.

62 Haskell WL, Alderman EL, Fair JM, Maron DJ, Mackey SF, Superko HR, Williams PT, Johnstone IM, Champagne MA, Krauss RM, Farquhar JW: Effects of intensive multiple risk factor reduction on coronary atherosclerosis and clinical cardiac events in men and women with coronary artery disease. The Stanford Coronary Risk Intervention Project (SCRIP). Circulation 1994;89:975-990.

63 Ornish D: Avoiding revascularization with lifestyle changes: The Multicenter Lifestyle Demonstration Project. Am J Cardiol 1998; 82:72T-76T

64 Aldana SG, Greenlaw R, Thomas D, Salberg A, DeMordaunt T, Fellingham GW, Avins AL: The influence of an intense cardiovascular disease risk factor modification program. Prev Cardiol 2004;7:19-25.

65 Kappagoda CT, Ma A, Cort DA, Paumer L, Lucus D, Burns J, Amsterdam E: Cardiac event rate in a lifestyle modification program for patients with chronic coronary artery disease. Clin Cardiol 2006;29:317-321.

66 Gulliksson M, Burell G, Vessby B, Lundin L, Toss H, Svärdsudd K: Randomized controlled trial of cognitive behavioral therapy vs. standard treatment to prevent recurrent cardiovascular events in patients with coronary heart disease: Secondary Prevention in Uppsala Primary Health Care project (SUPRIM). Arch Intern Med 2011;171:134-140.

67 Rankin P, Morton DP, Diehl H, Gobble J, Morey P, Chang E: Effectiveness of a volunteerdelivered lifestyle modification program for reducing cardiovascular disease risk factors. Am J Cardiol 2012;109:82-86.
68 Sebregts EH, Falger PR, Bär FW: Risk factor modification through nonpharmacological interventions in patients with coronary heart disease. J Psychosom Res 2000;48:425-441.

69 Friedman M, Rosenman RH: Association of specific overt behavior pattern with blood and cardiovascular findings; blood cholesterol level, blood clotting time, incidence of arcus senilis, and clinical coronary artery disease. JAMA 1959;169:1286-1296.

70 Rozanski A, Blumenthal JA, Kaplan J: Impact of psychological factors on the pathogenesis of cardiovascular disease and implications for therapy. Circulation 1999;99:2192-2217.

71 Fava GA, Freyberger HJ, Bech P, Christodoulou G, Sensky T, Theorell T, Wise TN: Diagnostic criteria for use in psychosomatic research. Psychother Psychosom 1995;63:1-8.

72 Rafanelli C, Roncuzzi R, Finos L, Tossani E, Tomba E, Mangelli L, Urbinati S, Pinelli G, Fava GA: Psychological assessment in cardiac rehabilitation. Psychother Psychosom 2003; 72:343-349.

73 Sirri L, Fava GA: Diagnostic criteria for psychosomatic research and somatic symptom disorders. Int Rev Psychiatry 2013;25:19-30.

74 Sirri L, Fava GA, Guidi J, Porcelli P, Rafanelli C, Bellomo A, Grandi S, Grassi L, Pasquini P, Picardi A, Quartesan R, Rigatelli M, Sonino $\mathrm{N}$ : Type A behaviour: a reappraisal of its characteristics in cardiovascular disease. Int J Clin Pract 2012;66:854-861.

75 Barrick CB: Sad, glad, or mad hearts? Epidemiological evidence for a causal relationship between mood disorders and coronary artery disease. J Affect Disord 1999;53:193-201.

76 Oedegaard KJ, Neckelmann D, Fasmer OB: Type A behaviour differentiates bipolar II from unipolar depressed patients. J Affect Disord 2006;90:7-13.

77 Wang Y, Terao T, Hoaki N, Goto S, Tsuchiyama K, Iwata N, Yoshimura R, Nakamura J: Type A behavior pattern and hyperthymic temperament: possible association with bipolar IV disorder. J Affect Disord 2011;133:2228.

78 Fiedorowicz JG, Solomon DA, Endicott J, Leon AC, Li C, Rice JP, Coryell WH: Manic/ hypomanic symptom burden and cardiovascular mortality in bipolar disorder. Psychosom Med 2009;71:598-606.

79 Fiedorowicz JG, Coryell WH, Rice JP, Warren LL, Haynes WG: Vasculopathy related to manic/hypomanic symptom burden and first-generation antipsychotics in a sub-sample from the collaborative depression study. Psychother Psychosom 2012;81:235-243.

80 Dubovsky SL: Treatment of bipolar depression. Psychiatr Clin North Am 2005;28:349370.

81 Fava GA, Tomba E, Tossani E: Innovative trends in the design of therapeutic trials in psychopharmacology and psychotherapy. Prog Neuropsychopharmacol Biol Psychiatry 2013;40:306-311. 
82 Sirri L, Fava GA, Sonino N: The unifying concept of illness behavior. Psychother Psychosom 2013;82:74-81.

83 Fava GA, Tomba E, Grandi S: The road to recovery from depression - don't drive today with yesterday's map. Psychother Psychosom 2007;76:260-265.

84 Whalley B, Rees K, Davies P, Bennett P, Ebrahim S, Liu Z, West R, Moxham T, Thompson DR, Taylor RS: Psychological interventions for coronary heart disease. Cochrane Database Syst Rev 2011;8:CD002902.
85 Friedman M, Thoresen CE, Gill JJ, Ulmer D, Powell LH, Price VA, Brown B, Thompson L, Rabin DD, Breall WS, Bourg E, Levy R, Dixon T: Alteration of type A behavior and its effect on cardiac recurrences in post myocardial infarction patients: summary results of the recurrent coronary prevention project. Am Heart J 1986;112:653-665.

86 Nunes EV, Frank KA, Kornfeld DS: Psychologic treatment for the type A behavior pattern and for coronary heart disease: a metaanalysis of the literature. Psychosom Med 1987;49:159-173.

87 Horwitz RI, Horwitz SM: The coronaryprone behavior pattern. Achievements and missed opportunities. Arch Intern Med 1986; 146:1429-1433.
88 Fava GA: Clinical judgment in psychiatry. Requiem or reveille? Nord J Psychiatry 2013;67: $1-10$.

89 Czarny MJ, Arthurs E, Coffie DF, Smith C, Steele RJ, Ziegelstein RC, Thombs BD: Prevalence of antidepressant prescription or use in patients with acute coronary syndrome: a systematic review. PLoS One 2011;6:e27671.

90 Fava GA, Rafanelli C, Tomba E: The clinical process in psychiatry: a clinimetric approach. J Clin Psychiatry 2012;73:177-184.

91 Tomba E, Bech P: Clinimetrics and clinical psychometrics: macro- and micro-analysis. Psychother Psychosom 2012;81:333-343. 